\title{
The comparison on complications from suprapubic vs. transurethral urinary diversion after hypospadias repair: Meta-analysis
}

\author{
Samudra Widagdo Arifin ${ }^{\mathrm{b}}$, Mohammad Ayodhia Soebadi ${ }^{\mathrm{a}, \mathrm{b}}$, Tarmono Djojodimedjo ${ }^{\mathrm{b}}$ \\ a samtatto86@yahoo.co.id \\ ${ }^{\mathrm{b}}$ Department of Urology, Medical Faculty, Airlangga University/Dr. Soetomo General Hospital, Surabaya, 60286, Indonesia
}

\begin{abstract}
Background: Urinary diversion post hypospadias repair plays an important role in the prevention of complications. This study objective was to analyze the comparison among suprapubic versus transurethral urinary diversion in preventing the complications after hypospadias repair. We aimed to compare the complications from suprapubic urinary diversion and transurethral urinary diversion in patients after hypospadias repair.
\end{abstract}

Methods: A systematic search was conducted in PUBMED and Google Scholar databases to identify relevant randomized controlled trials (RCTs). The subjects were studies that involved post-operative hypospadias patients. Compared outcomes were the incidence of urethrocutaneous fistula, meatal stenosis, and repair disruption. The approach to systematic study began with the use of PRISMA protocol based on inclusion and exclusion criteria. Meta-analysis was performed based on pooled analysis. Visualizations of each study were described with forest plots.

Results: There were two RCTs that met the criteria for quantitative analysis. Forest plot analysis showed the use of suprapubic diversion might significantly lower the risk of urethrocutaneous fistula (OR $0.22,95 \%$ CI $0.05-0.89, \mathrm{p}=0.03$ ). Meatal stenosis and repair disruption between the two studies did not differ significantly.

Conclusion: There was a significantly lower incidence of urethrocutaneous fistula in postoperative hypospadias patients who performed suprapubic urine diversion compared to those who received transurethral urine diversion. The difference in the incidence of meatal stenosis and repair disruption was insignificant between the two groups of urine diversion.

Keywords: Urinary Diversion, Hypospadia, Suprapubic Urinary Diversion, Transurethral Urinary Diversion

\section{Introduction}

The prevalence of hypospadias in Asia represented by research from China (0.7-4.5/10,000 live births) and Koreans (1.4-3.3/10,000 live births) are lower than prevalence in Europe and America (18-39/10,000 live births).[1] In the last 25 years, various techniques of hypospadias surgery have been much developed, but the incidence rate of complications remains stable at around 10\%. Urethroplasty treatment in hypospadias provides a wide risk of complications including urethrocutaneous fistula, glans dehiscence, meatal stenosis, urethral stricture, urethral diverticulum, balanitis, and complications of the skin. Overall, the incidence of complications reached $10.6 \%$ with a reoperation rate of 4.5\%.[2] Urethrocutaneous fistula is one of the most common complications occurred, with incidence rates ranging between 5.7-10\%.[2,3] Improper wound healing due to hematoma, infection, overly tense approximation, urine extravasation, ischemia, necrosis, or improper use of stitching materials can all result in urethrocutaneous fistula.[4] Various studies had given different results from the use of urinary diversions as well as stents in the prevention of urethrocutaneous fistula. Which type of urine diversion to use is still a debate.[5] The purpose of urinary diversion is to prevent edema in the urethra that may obstruct urinary flow. Some of the diversion types including perineal urethrostomy, suprapubic cystotomy, foley catheter, and transurethral drainage. Cystotomy suprapubic is often used related to its easier installation and rarely cause spasm on bladder. It also does not has contact with surgical wounds and can be used for a longer period of time.[6] Transurethral urinary diversion also has several advantages, such as prevention of urinary retention, which can be functionated as a bleeding tampon and stent at the same time, so that gives better re-epithelization. However, the installation of a transurethral catheter may provide pain, often causing spasm of the bladder, and a greater risk of infection, especially due to the extravasation of urine from the sidelines of the catheter. The installation of transurethral catheters also presents a risk of damage to the neourethral at the time of release.[6,7] Some researchers suggest the use of suprapubic urinary diversion is safer and more comfortable than a transurethral urinary diversion but increases the duration of treatment. The incidence of complications other than urethrocutaneous fistula is also said to be lower in transurethral catheter suprapubic cystotomy.[10] Therefore further analyses on the use of urinary diversion are needed. 


\section{Materials and Methods}

PUBMED, Google Scholar or national publications in Indonesian and English were searched in order to identify article which had been published. The timing of journal selection was unlimited. The literature used includes randomized controlled trial (RCT) studies. The search system is limited to English and Indonesian journals. The search terms using medical subject heading (MeSH) and free text with keywords((hypospadia OR hypospadias) AND (urethroplasty OR urethroplasties) AND (urine OR urinary) AND (diversion) AND (cystostomy OR suprapubic catheter) AND (fistula). The samples were all research with subjects of hypospadias patients who had undergone surgery. The compared outcomes were the incidence of urethrocutaneous fistula, meatal stenosis, and repair disruption from the subjects who had performed suprapubic or transurethral urinary diversion. The approaching method to systematic study was initiated by using The Preferred Reporting Items for Systematic Reviews and MetaAnalysis (PRISMA) protocol. We used the following inclusion criteria to determine the eligibility of studies: (1) Randomized Controlled Trial (RCT) study design, (2) Studies on the incidence of urethrocutaneous fistula, meatal stenosis, and repair disruption in postoperative hypospadias patients who had performed suprapubic urine diversion compared to transurethral urine diversion (catheterization of the urethra and transurethral stents), (3) Studies can include hypospadias surgery with a variety of surgical techniques, and (4) Studies with 2 or more arms. Studies with following criteria were excluded: (1) Review article, (2) Animals studies, (3) Abstract only articles, (4) Retrospective and non-RCT studies. Bias analysis will be conducted in each journal used the method of Cochrane Risk Of Bias Tools In Form Randomized Trial which will divide the research risk based on selection bias, performance bias, detection bias, report bias and attrition. Quality assessment of each journal is conducted based on research methods, implementation, statistical analysis and results. All selected journals will be extracted and tabulated to analyze the necessary outcomes. The merger of the results is done by codifying each study that has been selected for systematic comparison.

\section{Statistical analysis}

All selected articles will be presented in the form of baseline characteristic data with distribution on each article used. All baseline characteristics such as the name of the researcher, year of research, research design, number of samples in each arms, average age of the each subjects, techniques of hypospadias repair surgery, type of urinary diversion, incidence rate of urethrocutaneous fistula, incidence rate of meatal stenosis, and repair disruption will be shown in this study. Statistical analysis based on pooled analysis was used to compare variables in each research journal. The visualization of each study would be described in the forest plot. The numerical data with normal distribution will be displayed in the form of average and standard deviation. In the dichotomy data, the number of proportions and samples used in each study will be analyzed as the hazard ratio (HR) of each variable. All data processing used RevMan ver 5.4 for windows software.

\section{Results}

Systematic searching method was described in figure 1, based on PRISMA guidelines on google scholar and PUBMED databases. The initial search resulted in 292 articles. From all of the articles, there were duplicates databases. At the end of the searching process, there were two RCTs that met the criteria for quantitative analysis. The number of samples obtained from both studies was 127 patients. The RCT included in this systematic review compared the two urinary diversion procedures in cases of distal and middle hypospadias. Qamar et al added a comparison group with patients who received suprapubic diversion treatment with the installation of catheters intra urethra.[9,11] The basic characteristics of the samples studied in the RCT are shown in table 1. The basic characteristics of the samples of the two RCTs are divided by age in table 2. There were no significant differences between the average parameters of basic characteristics between studies. The parameters evaluated in this study were shown in table 3. For other complications parameters that were only reported on one RCT could not be analyzed further. This meta-analysis used the Cochrane Risk of Bias (ROB) Tools For Randomized Trials instrument to evaluate the level of bias in each RCT. Samples following the study performed randomization to determine the intervention given. The overall bias analysis resulted from both RCTs were shown in figure 2 and figure 3. After the randomization process, the allocation results should not be conveyed to the patient to minimize the possibility of bias due to suggestions. But the confidentiality of the allocation was only mentioned in the study by Radwan et al, while Qamar et al did not explain the method or the results, whether the confidentiality of the allocation has been done. Forest plot analysis that evaluated the difference in the incidence of urethrocutaneous fistula between suprapubic and transurethral diversions was described in figure 4. It showed significant differences in results (OR $0.22,95 \%$ CI $0.05-0.89, \mathrm{p}=0.03)$. The use of suprapubic diversions can lower the risk of such complications. The analysis was conducted using a fixed model due to low heterogeneity $\left(\mathrm{I}^{2}=0 \%\right)$. Otherwise, the forest plot analysis regarding meatal stenosis from both articles were described in figure 5. The average difference in meatal stenosis complications between the two articles showed results that did not differ significantly (OR 1.59, 95\% CI 0.53-4.80, $\mathrm{p}=0.41)$. The analysis model used was random-effects due to heterogeneity between the two studies $\left(\mathrm{I}^{2}=61 \%\right)$. There was also an insignificant difference in the number of repair disruption complications between the two groups (OR $0.44,95 \%$ CI $0.10-2.02, \mathrm{p}=0.29$ ). The fixed-effects model was used due to the high homogeneitywbeitweęs the two studies $\left(\mathrm{I}^{2}=98 \%\right)$. The forest plot was described in figure 6 . 
Articles identified from a systematic search in Pubmed, $(n=239)$, Google Scholar $(n=53)(n=292)$
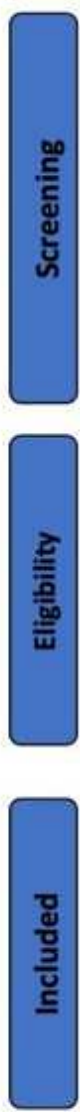

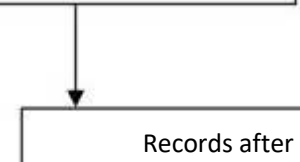

Additional records identified through symposiums or national meetings $(n=1)$ $(n=283)$
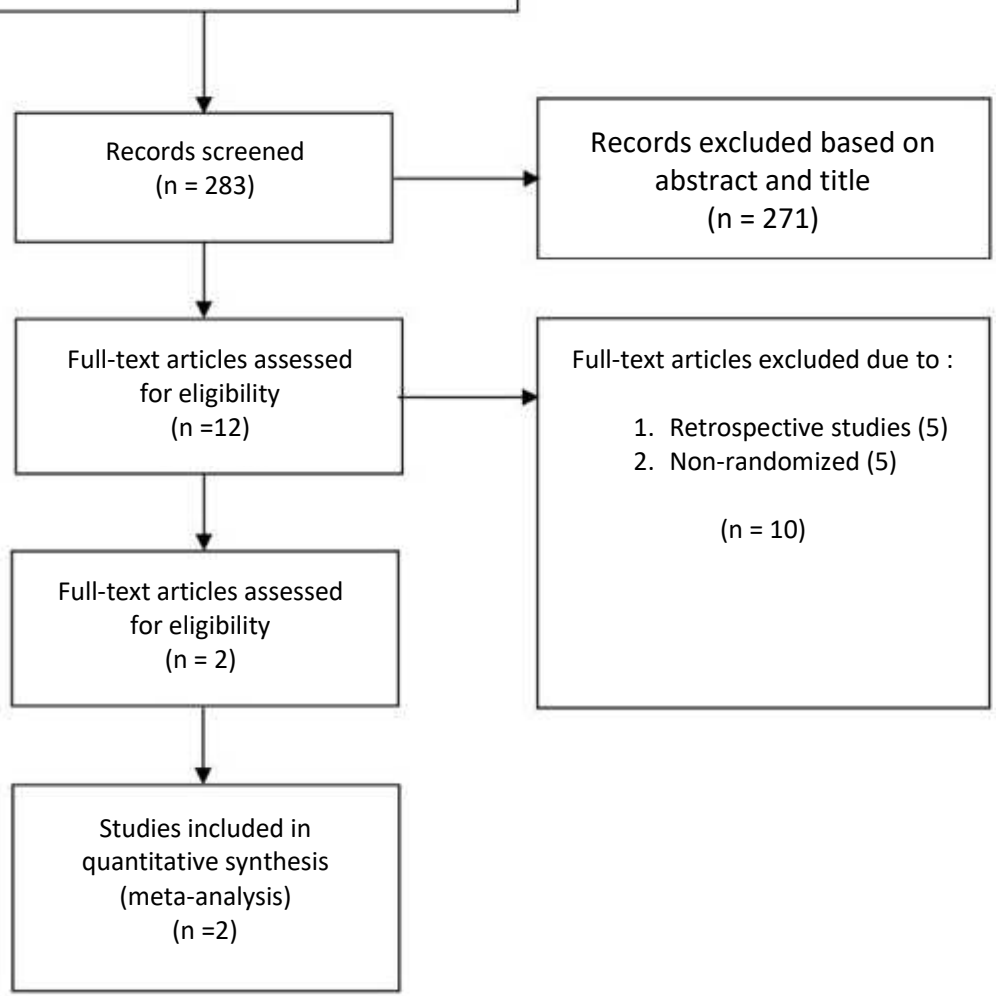

Fig. 1. PRISMA flow diagram

Table 1. Characteristics of the study articles

\begin{tabular}{|c|c|c|c|c|c|c|}
\hline \multirow{2}{*}{ Study (years) } & \multicolumn{2}{|c|}{ Average age (years) } & \multicolumn{2}{|c|}{$\begin{array}{c}\text { Duration of Hospitalization } \\
\text { (days) }\end{array}$} & \multicolumn{2}{|c|}{ Average Follow up time (month) } \\
\hline & Suprapubic & Transurethral & Suprapubic & Transurethral & Suprapubic & Transurethral \\
\hline Radwan et al, 2012 & $4.9 \pm 2.5$ & $3.3 \pm 1.6$ & \multicolumn{2}{|c|}{$4.5 \pm 1.8$} & \multicolumn{2}{|c|}{$21.5 \pm 10.1$} \\
\hline Qamar et al 2013 & \multicolumn{2}{|c|}{$3 \pm 0.75$} & & 3 & \multicolumn{2}{|c|}{$3-18$} \\
\hline
\end{tabular}


Table 2. Characteristic of the study articles based on age of the subjects

\begin{tabular}{|c|c|c|c|c|c|c|c|}
\hline \multirow{2}{*}{ Study (years) } & \multirow{2}{*}{$\begin{array}{l}\text { Types of } \\
\text { Studies }\end{array}$} & \multirow{2}{*}{$\begin{array}{c}\text { Large } \\
\text { sample }\end{array}$} & \multirow{2}{*}{$\begin{array}{c}\text { Types of } \\
\text { Interventions }\end{array}$} & \multirow{2}{*}{$\begin{array}{c}\text { Hypospadias } \\
\text { Type }\end{array}$} & \multirow{2}{*}{$\begin{array}{c}\text { Repair } \\
\text { Procedure }\end{array}$} & \multicolumn{2}{|c|}{ Distribution of samples by intervention } \\
\hline & & & & & & Suprapubic & Transurethral \\
\hline $\begin{array}{c}\text { Radwan et al, } \\
2012\end{array}$ & $\mathrm{RCT}$ & 67 & $\begin{array}{l}\text { Suprapubic } \\
\text { and } \\
\text { transurethral }\end{array}$ & $\begin{array}{c}\text { Distal dan } \\
\text { Middle } \\
\text { hypospadias }\end{array}$ & $\begin{array}{c}\text { TIP, } \\
\text { Mathieu's, } \\
\text { miscellaneous }\end{array}$ & 33 & 34 \\
\hline $\begin{array}{c}\text { Qamar et al, } \\
2013\end{array}$ & $\mathrm{RCT}$ & 60 & $\begin{array}{l}\text { Suprapubic, } \\
\text { transurethral, } \\
\text { and } \\
\text { combination } \\
\text { diversions }\end{array}$ & Distal & $\begin{array}{c}\text { Snodgrass } \\
\text { TIP }\end{array}$ & 63 & 63 \\
\hline
\end{tabular}

Table 3. Evaluation of complication parameters from both articles

\begin{tabular}{|c|c|c|c|c|c|}
\hline \multirow{2}{*}{ Study (years) } & \multicolumn{2}{|c|}{ Urethrocutaneous Fistula } & \multicolumn{3}{|c|}{ Meatal stenosis } \\
\hline & Suprapubic & Transurethral & Suprapubic & Transuret & \\
\hline Radwan et al, 2012 & $2(63)$ & $8(63)$ & $8(62)$ & $3(63)$ & \\
\hline Qamar et al, 2013 & $0(30)$ & $2(30)$ & $0(30)$ & $2(30)$ & \\
\hline \multicolumn{6}{|c|}{ Random sequence generation (selection bias) } \\
\hline \multicolumn{6}{|c|}{ Allocation concealment (selection bias) } \\
\hline \multicolumn{6}{|c|}{ Blinding of participants and personnel (performance bias) } \\
\hline \multicolumn{6}{|c|}{ Blinding of outcome assessment (detection bias) } \\
\hline \multicolumn{6}{|c|}{ Incomplete outcome data (attrition bias) } \\
\hline \multicolumn{6}{|c|}{ Selective reporting (reporting bias) } \\
\hline \multicolumn{6}{|c|}{ Other bias } \\
\hline & & $0 \%$ & $25 \%$ & $75 \%$ & $100 \%$ \\
\hline Low risk of bias & Un & r risk of bias & High risk of & & \\
\hline
\end{tabular}

a

\section{Repair Disruption}




\section{Suprapubic Transurethral Odds Ratio}

Odds Ratio

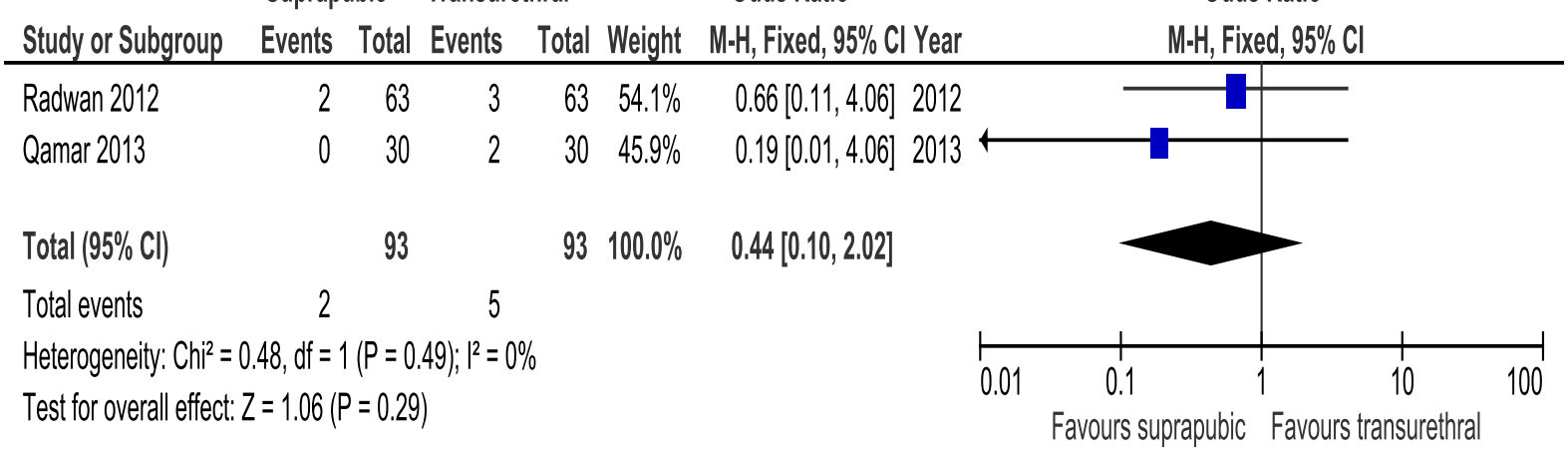

Figure 4. Forest plot analysis of the meatal stenosis incidence from both studies

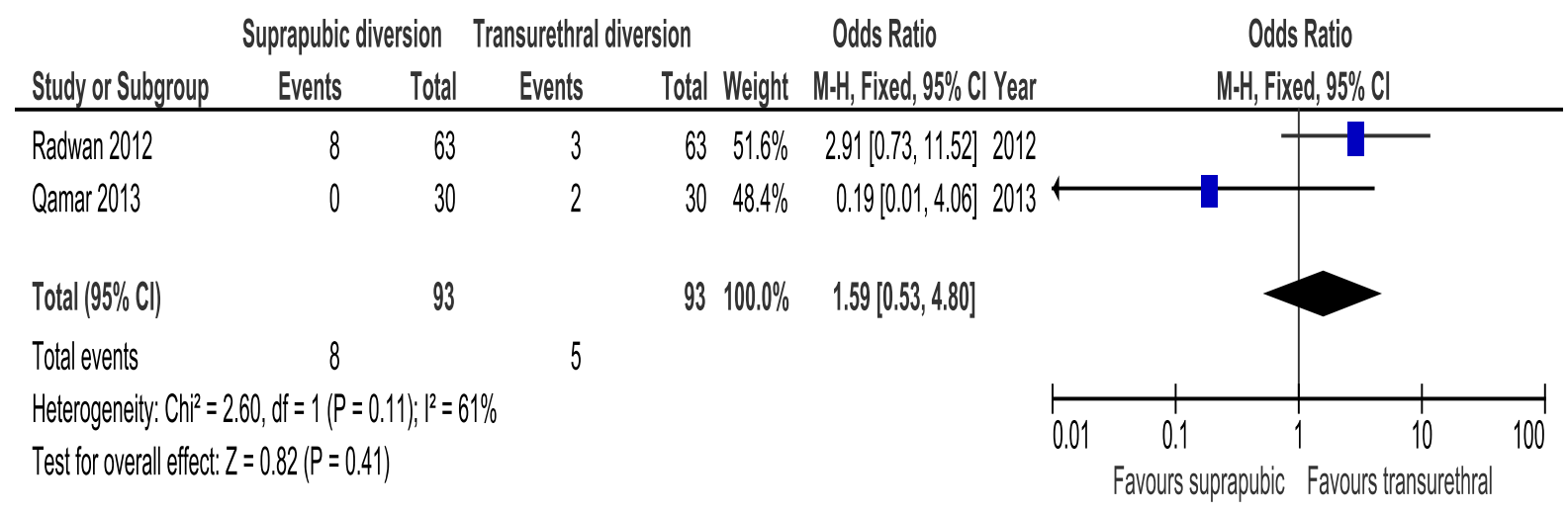

Figure 5. The forest plot of repair disruption risk from both studies

\section{Discussion}

A transurethral catheter, either for catheterization to the bladder or as a stent, was the most common form of urine diversion. Similarly, the use of a suprapubic catheter is also frequent. To date, the comparisons of these methods have been conflicting. Zhang et al reported that the use of urinary diversion after one-stage surgery can be useful for spontaneous closing of small urethrocutaneous fistulas and may prevent the formation of new fistulas.[12] Almodhen et al and Joshi et al also reported good results on postoperative urinary diversion using Mathieu and TIP urethroplasty techniques.[13,14] Otherwise, according to Geryimanoglu et al, Sigumonrong et al, and De Badiola et al, neither transurethral urinary diversion with catheters or stents, nor suprapubic diversion, may lower the risk of postoperative complications, such as urethrocutaneous fistulas. The incidence rate of postoperative hypospadia fistulas did not differ significantly.[15-17] Retrospective, prospective, and RCT studies have different conclusions. Because retrospective and prospective studies are more likely to be biased than RCTs, this analysis only considered RCTs. From both RCT the incidence of complications of urethrocutaneous fistula was significantly higher in the group with transurethral urinary diversion (OR $0.22,95 \%$ CI $0.05-0.89, p=0.03$ ). However, the incidence of meatal stenosis and repair disruption did not have a significant difference between the two groups ( $p>0.05)$. Both urinary diversion types have their own advantages and disadvantages. The meatal stenosis incidence looks very different between these two RCT studies. This can be due to many other factors that might affect the occurrence of meatal stenosis. Postoperative treatment in patients in the Radwan et al was not the same as postoperative treatment in the Qamar et al study. Postoperative care was not clearly mentioned in those studies. The incidence of stenosis on Radwan et al might relate to the group of suprapubic urinary diversion which also combined with anterior urethral stent. These insignificant results in meatal stenosis between the two studies were partly due to the small number of samples in each study.[9,11] This meta-analysis has several limitations, including a small number of RCT studies, the number of samples from each study, and limited evaluation results. In this study, only distal hypospadias was included. Hypospadias could be classified as granular type, distal type, and proximal type. A lot of studies have been performed, but the RCT method is only found in the study of distal hypospadias. The study of proximal hypospadias and urine diversion is more common, but the majority of these studies were retrospective and prospective without randomization. Thus, the resulted parameters are still behind the RCT. The evaluation of complications from those studies were not exactly the same, so that, the analysis could be done only on the same complications. Some complications such as trigonum pain and cosmetic satisfaction evaluation were evaluated in the Qamar et al, but were not reported by Radwan et al. Analysis of those factors cannot be performed. 


\section{Conclusion}

The incidence of urethrocutaneous fistula was lower in the group which suprapubic urinary diversion post hypospadias surgery were performed. The incidence of meatal stenosis and urinary disruption from both studies were insignificantly different.

\section{Acknowledgement}

None.

\section{References}

[1] Bergman JEH, Loane M, Vrijheid M, Pierini A, Nijman RJM, Addor MC, et al. Epidemiology of Hypospadias in Europe: a RegistryBased Study. World J Urol. 2015;33:2159-67.

[2] Pfistermuller KLM, McArdle AJ, Cuckow PM. Meta-Analysis of Complication Rates of The Tubularized Incised Plate (TIP) Repair. J Pediatr Urol. 2015;11:54-9.

[3] Laura SF, Duarsa GWK, Mahadewa TG. Correlation of Cystostomy to Low Urethrocutaneous Fistula Incident in Hypospadia Surgery. Bali Medical Journal. 2014;3:125-28.

[4] Sen B, Adayener C, Akyol I. Repairing Urethrocutaneous Fistula in Adults: Is a Catheter Necessary? Urology. $2007 ; 70: 239-41$.

[5] Bhat A. General Considerations in Hypospadias Surgery. Indian Journal of Urology. 2008;24:188-94.

[6] Hadidi A, Azmy A. Hypospadias Surgery An Illustrated Guide. Hypospadias Surgery. New York: Springer-Verlag Berlin Heidelberg; 2004. 269-270 p.

[7] Aslan AR, Yücebaş E, Tekin A, Şengör F, Kogan BA. Short-term Catheterization After TIP Repair in Distal Hypospadias: Who Are The Best Candidates? Pediatr Surg Int. 2007;23:265-9.

[8] Sigumonrong YH, Santoso A, Djojodimedjo T, P WJ. Perbedaan Angka Kejadian Fistel Uretrokutan Pada Penggunaan Kateter Uretra Dan Kateter Suprapubik Dengan Stent Setelah Operasi Hipospadia. Indones J Urol. 2009;16:53-7.

[9] Qamar SA, Pansota MS, Rasool M, Tabassum SA, Saleem MS. Urinary Diversion in Hypospadias Repair: Suprapubic Cystostomy versus Transurethral Catheterization. Pak Armed Forces Med J. 2013;63:75-9.

[10] Osifo OD, Azeez AL. Outcomes of Transurethral and Suprapubic Urinary Diversion Following Hypospadias Repair in Children. Pakistan J Med Sci. 2010;26:329-34.

[11] Radwan M, Soliman MG, Tawfik A, Abo-Elenen M, El-Benday M. Does The Type of Urinary Diversion Affect The Result of Distal Hypospadias Repair? A Prospective Randomized Trial. Ther Adv Urol. 2012;4:161-5.

[12] Zhang J, Li S, Chen X. Urinary Diversion in The One Stage Hypospadia Repair. Chinese J Plast Surg Burn. 1999;15:140-1.

[13] Almodhen F, Alzahrani A, Jednak R, Capolicchio JP, El Sherbiny MT. Nonstented Tubularized Incised Plate Urethroplasty with Y-toI Spongioplasty in Non-Toilet Trained Children. Can Urol Assoc J. 2008;2:110.

[14] Joshi A, Surana RS. Prospective Randomised Study of Stented versus Unstented Mathieu Repair of Hypospadias. Internet J Urol. 2006;3:1-3.

[15] Germiyanoğlu C, Nuhoğlu B, Ayyildiz A, Akgül KT. Investigation of Factors Affecting Result of Distal Hypospadias Repair: Comparison of Two Techniques. Urology. 2006;68:182-5.

[16] Sigumonrong YH, Santoso A, Djojodimedjo T, Pudjirahardjo WJ. Perbedaan Angka Kejadian Fistel Uretrokutan pada Penggunaan Kateter Uretra dan Kateter Suprapubik dengan Stent Setelah Operasi Hipospadia. Indones J Urol. 2009;16:53-7.

[17] de Badiola F, Anderson K, Gonzalez R. Hypospadias Repair in An Outpatient Setting without Proximal Urinary Diversion: Experience with 113 Urethroplasties. J Pediatr Surg. 1991;26:461-5. 